\title{
EXPLORANDO OS LIMITES \\ DA EXTENSÃO DE MARCAS
}

\section{EXPLORING BRAND EXTENSION}

MA G DA RIBEIRO

Publicitária, formada pela PUC - Campinas. Especialista em marketing pela Universidade Presbiteriana Mackenzie. Atua como Gerente de Produto na $3 \mathrm{M}$ do Brasil. Professora de Comunicação Social nas Faculdades Unopec. Av. Império do Sol Nascente, 522, ap. 73, Jardim Aurélia - Campinas - SP -

CEP 130330-050

E-mail:meg_ribeiro@yahoo.com 


\section{RESUMO}

Este trabalho tem como objetivo o estudo das estratégias de extensão de marca e seu papel para a competitividade, bem como a percepção dos consumidores relativa a esta estratégia. O trabalho é norteado pelo tripé: marca-produto-consumidor. Inclui estudos que visam explorar e conceituar a estratégia de extensão de marca; identificar as diferenças entre extensão de marca e extensão de linha; apresentar os riscos e benefícios desta estratégia; e por fim entender a percepção dos consumidores relativa à prática da extensão. O tema deste estudo é bastante relevante para o meio acadêmico e profissional, uma vez que a prática da extensão tem se tornado cada vez mais comum e presente nas decisões estratégicas relativas às marcas. A era é da extensão e não mais da criação de novas marcas. Como se trata de uma pesquisa teórica, são utilizados livros, textos e artigos dos principais autores que tratam de extensão de marca no Brasil e no mundo.

\section{PALAVRAS = CHAVE}

Marcas; Extensão de marca; Produtos; Consumidor.

\section{ABSTRACT}

The main purpose of this paper is to study the brand extension strategy and his hole in competitive as well as customer perception related to this strategy. Including the studies that explore the conceptions of brand extension strategy, the identification of the differences related to brand extension and product line extension strategy, and finally the customer perception related this strategy. This paper still included an analysis about which are the benefits and risks that brand extension strategy brings to companies and consumer. The theme of this paper is relevant to the academic and professional sphere, as the brand extension strategy have become usual inside companies. As this paper is a theoretical research it will be used books, texts and papers of the main authors of brand extension strategy of Brazil and the world. The corporate investment growth in brand ex- 
tension and products portfolio justifies the concerning with this theme, now we are in brand extension era, and not of new brands creation.

\section{KEYWORDS}

Brands; Brand extension; Products; Customer.

\section{INTRODUÇ ̃̃O}

Em nossa atual conjuntura de empresas globais, cujo astronômico crescimento dos últimos I5 anos se alastra por este século, uma afirmação pode ser feita a partir da inócua idéia desenvolvida por teóricos da administração em meados de I980: as corporações de sucesso devem produzir principalmente marcas e não produtos.

No final da década de I940, surgiu a consciência de que a marca não era apenas um símbolo ou uma imagem impressa na etiqueta do produto; toda empresa poderia e gostaria de ter impregnado em sua marca a representação de sua "consciência corporativa", o que parecia ser de importância fundamental, uma vez que as empresas poderiam fabricar produtos, mas o que interessava aos consumidores eram as marcas. Levaram algumas décadas para que o mundo da fabricação se adaptasse a esta mudança; por muito tempo, ele se manteve fiel à idéia de que seu negócio essencial ainda era a produção e que a marca era apenas uma mera contribuição.

Na década de I980, houve uma reviravolta na geração de marcas, e os diretores das grandes corporações tomaram consciência que, a partir dali, o grande ativo de suas empresas estava em suas marcas. O que nos faz crer que a marca passou a ocupar uma posição de destaque e de sustentação para o crescimento corporativo; desta forma, a importância da discussão sobre o gerenciamento de marca torna-se impreterível.

Ocorreu na economia brasileira, em todos os setores, a redução das margens de lucro, o que fez com que os empresários buscassem de todas as maneiras reduzir os custos. Por ser parte integrante e fundamental no processo de diferenciação do negócio, a marca - se estabelecida com sucesso - pode transformar-se em vantagem na determinação do preço e do serviço.

A marca, nos dias de hoje, não deve ser administrada somente como um desenho a partir de um olhar puramente gráfico. Na verdade, a marca é constituída por todos os pontos de contato entre ela e o consumidor, pelo modo como o telefone é atendido na empresa, pela postura da equipe de vendas, pelas informações contidas na embalagem, pelo cartão de visita; ou seja, a cada vez que o cliente interage com a empresa, com seus serviços e produtos, o reflexo é projetado na marca. 
Este estudo visa fazer uma análise bibliográfica dos principais autores que tratam das extensões de marca. Busca também entender como tais extensões agem sobre a ampliação de linhas de produtos, bem como seu impacto na percepção dos consumidores.

A importância que vem sendo atribuída ao bom gerenciamento da marca acarreta o desdobramento de estudos e análises acerca deste tema. Observando o atual cenário das divisões de marketing das grandes empresas, podemos apontar alguns tópicos com destaque: I. o número de marcas e de concorrentes em diversas categorias de produtos tem se alastrado de maneira dinâmica e ameaçadora; 2. os investimentos em comunicação estão tornando-se cada vez mais otimizados e precisam ser mais assertivos para surtirem resultado; 3. a preocupação empresarial constante com o crescimento das corporações e a geração de novos negócios.

O estudo aqui apresentado circunda em torno do tripé marca-produto-consumidor, é iniciado com um breve histórico sobre a utilização da marca pelas empresas em nosso atual cenário mercadológico, apresenta a marca e suas definições, aborda ainda importantes temas como brand equity, estratégias relativas à marca, entre outros. Com isso, o leitor é preparado para imersão nos conhecimentos sobre a extensão de marca, conhece a estratégia da extensão, diferencia extensão de marca de extensão de linha, chegando aos conceitos e classificações da extensão, passando ainda por tópicos que abordam os riscos e os benefícios desta estratégia. Para concluir o tripé proposto, abordar-se-á também a percepção dos consumidores sobre a estratégia de extensão de marca.

\section{AS MARCAS}

\subsection{ENTENDENDO E CONTEXTUALIZANDO AS MARCAS}

Segundo Kotler (2000, p. 37), todas as atividades desenvolvidas por uma empresa podem ser classificadas como mix de marketing, esse mix é constituído por inúmeras atividades. Kotler (2003, p. 58) cita a definição proposta, no início da década de I960, pelo professor Jerome McCarty, que se tornou consagrada pelo desenvolvimento que lhe foi atribuído por aquele. O mix de marketing consiste na junção de quatro ps: produto, preço, praça e promoção; cada p, por sua vez, abrange diversas atividades, dentre elas será dado destaque às atividades que competem ao $\mathrm{p}$ de produto. As atividades relacionadas ao produto resumem-se no gerenciamento da qualidade do produto, nas características físicas, nas embalagens, nos tamanhos e formatos, nas garantias, e na marca que lhe é atribuída. 
Dentro do mix de marketing, a marca é um dos elementos que merece maior destaque nos dias de hoje, justamente por desempenhar um papel fundamental para a competitividade.

\section{2 -2 O QUE É UMA MARCA}

Marca, segundo Aaker (I998, p. 7), é um nome diferenciado e/ou símbolo, podendo ser representado por um logotipo, marca registrada, ou desenho de embalagem, destinado a identificar os bens ou serviços de um vendedor ou grupo de vendedores, além de diferenciar esses bens e/ou serviços de seus concorrentes. Desta forma, uma marca pode sinalizar ao consumidor a origem do produto comprado.

De acordo com Kotler (2003, p. 72), são grandes os benefícios resultantes da construção de uma marca organizacional, ou seja, uma marca que possa representar uma corporação. Atualmente a marca está elevada ao mais alto grau de diferenciação e representação corporativa e é gerenciada não apenas pelas funções primárias de seu surgimento, mas sim por ser considerada hoje, acima de tudo, uma potencial ferramenta geradora de lucratividade e de longevidade de produtos. Uma marca, portanto, pode ser mantenedora e sustentadora de um produto quando começar a surgir concorrentes com a mesma tecnologia, reduzindo a capacidade de diferenciação nas características puramente físicas do produto.

Segundo Kapferer (I998, p. 4I), a marca possui uma lógica diferente da produção; os esforços das empresas estão concentrados em atender seus clientes de maneira repetida e constante, oferecendo a eles atributos tangíveis e intangíveis, funcionais e hedonistas, visíveis e invisíveis, tudo isso a um preço acessível. O primeiro trabalho de reflexão sobre a marca volta-se para a definição precisa sobre exatamente o que a marca injeta nos produtos que a carregam. Este discurso pode parecer um tanto intrincado, mas ele nada mais é do que o completo entendimento sobre as diferenças percebidas no mesmo produto, com ou sem determinada marca.

Este significado profundo da marca, na maioria das vezes, é esquecido ou omitido e, com freqüência, a marca é estacionada no campo da superficialidade. A marca não é simplesmente um ator do mercado, ela deve ser um organizador movido por sua visão, missão e valores devidamente construídos.

Existem inúmeras definições para a marca. Jaime Troiano, sócio da Troiano Consultoria de Marcas, revelou em uma de suas palestras que a melhor definição atribuída a uma marca é compará-la a uma cebola. Cada parte da cebola é equivalente a um contato do consumidor com a marca em questão, ou seja, para Troiano a marca não possui uma essência, um caroço, mas sim pontos de contato que, em conjunto, formarão a percepção do consumidor. 


\subsection{BRAND EQUITY: MESURANDO O VALOR DA MARCA}

O brand equity pode ser traduzido como eqüidade da marca, e é hoje um dos tópicos mais atuais na administração contemporânea, não só pela necessidade crescente das empresas mensurarem seus gastos e retornos, mas também pela comprovação efetiva que o trabalho de gerenciamento de marcas propicia. $\mathrm{O}$ brand equity foi bem definido por Aaker (1998, p. I6):

Brand equity é um conjunto de ativos e passivos ligados a uma marca, seu nome e seu símbolo, que se somam ou se subtraem do valor proporcionado por um produto ou serviço para uma empresa e/ou para os consumidores dela.

Esta contabilização, segundo o autor, pode ser agrupada de forma prática em cinco categorias: I. lealdade à marca; 2. conhecimento do nome; 3. qualidade percebida; 4. associação à marca em acréscimo à qualidade percebida; e 5. outros ativos do proprietário da marca, como patentes, relações com os canais de distribuição etc.

Algumas empresas, durante suas contabilizações para mensurar o valor das marcas, chegaram a resultados que merecem destaque. De acordo com pesquisa realizada anualmente pela revista Businessweek e pela Consultoria Interbrands, Palladino (2004, p. 27) apresenta os resultados de 2004, quando a marca Coca-Cola foi avaliada em US\$ 67,3 bilhões de dólares; apesar do recuo de $4 \%$ com relação ao ano passado, ela ainda está em primeiro lugar no ranking, seguida pela marca Microsoft, avaliada em US\$ 6r,3 bilhões.

Este enfoque dado ao valor da marca é considerado de extrema importância por inúmeras razões. Além de as marcas serem compradas e vendidas, e para isso é necessário que elas tenham valores, os investimentos depositados em uma marca são em sua maioria altíssimos, o que justifica estes investimentos pode ser o crescente valor embutido em seu brand equity.

De acordo com Aaker (1998, p. 23), são propostos cinco enfoques gerais para se calcular o valor do brand equity. O primeiro deles baseia-se no premium price (preço superior), o que significa simplesmente observar os níveis de preço no mercado em produtos concorrentes e semelhantes; assim, se determinada marca de produto custa mais do que a de seus concorrentes, porém os atributos físicos do produto são muito parecidos, por alguma razão os consumidores depositam valor naquela marca. O segundo ponto baseia-se no impacto que o nome da marca possui na preferência do consumidor; assim, quando os produtos 
são semelhantes e possuem preços muito parecidos - como é o caso da categoria de cigarros, por exemplo -, verifica-se junto ao consumidor qual sua marca de preferência, sua atitude ou intenção de compra. O terceiro ponto volta-se para o valor da substituição da marca; assim, verifica-se qual é o preço pago pelos consumidores quando a decisão de trocar de marca é tomada - por exemplo, ao optar por outra empresa/marca de telefonia celular, o consumidor pode ter a necessidade de trocar de aparelho ou mesmo de refazer seus dados pessoais. No caso empresarial, esta análise pode ser feita partindo do princípio de que uma empresa deve avaliar o quanto custa construir uma nova marca versus a possibilidade de comprar uma que já está previamente estabelecida no mercado. Já o quarto ponto baseia-se no preço da ação; assim, é utilizado o preço das ações no mercado como base para estimar o valor do brand equity de uma empresa. $\mathrm{O}$ quinto e último ponto focaliza o poder de ganho que uma marca possui no futuro; um dos caminhos para isso é usar o plano de longo prazo da marca, considerando para tanto as forças da marca e seus impactos sobre o ambiente competitivo.

É inegável a necessidade das empresas mensurarem o valor de suas marcas; uma vez que estes foram estabelecidos como ativos, precisam ser mensurados e contabilizados como qualquer outro ativo empresarial.

\section{EXPLORANDO OS LIMITES DA EXTENSÃO DE MARCAS}

\subsection{ENTENDENDO A EXTENSÃO DE MARCAS}

Um dos mais difíceis desafios relativos às marcas é manter seu contínuo crescimento. Aparentemente, uma das formas mais fáceis de manter este crescimento seria pela introdução de novos produtos com a mesma marca e relativos à categoria de produtos da marca principal. Esta estratégia seria bastante óbvia e vencedora, se não fosse tão complexa e desafiadora.

Para Aaker (I998, p. 219), a extensão de marca se dá a partir da utilização de um nome de marca já estabelecido em um mercado ou categoria de produtos, para entrar em outro mercado ou categoria de produtos em que este não atua. O autor afirma ainda que a extensão de marca é uma estratégia natural para as empresas que pretendem crescer por meio de seus ativos. "Na verdade, os ativos mais reais e comercializáveis de muitas empresas são os nomes de marcas que desenvolveram."

Hoje em dia, a maioria das grandes empresas reconhece o valor e a importância de suas marcas como um de seus ativos mais importantes. Neste ambien- 
te competitivo, a extensão de marcas foi, por muito tempo, considerada uma estratégia cômoda e sem criatividade, que poderia inclusive prejudicar a marca principal em vez de ajudá-la.

Este cenário sofreu alterações e o assunto tornou-se cada vez mais explorado; com o devido cuidado, digamos, a extensão de marca passou a ser vista por muitos estudiosos da área como uma estratégia altamente lucrativa e uma poderosa forma de ampliação dos negócios das empresas, sem considerar seu alto potencial de fortalecimento da marca primogênita.

Para Kapferer (I998, p. 229), a extensão de marcas é resultante da concentração de esforços sobre algumas marcas, em vez do lançamento de uma nova marca para cada novo produto. Para o autor, quando a marca possui vocação para ser uma marca estratégica da empresa, os novos produtos deverão ser lançados sob a égide da marca já existente.

Para muitos gestores de marcas, esta estratégia está repleta de desafios, de questões como: Qual marca da empresa deve ser escolhida para um novo produto? Quais os fatores determinantes desta escolha? Qual mercado representa melhor oportunidade para as marcas da empresa? Qual estratégia deve ser adotada para um novo produto, em um novo mercado? E finalmente, de que forma a extensão de marca poderá afetar o valor e a imagem da marca principal? Estas, entre outras questões, rondam as mentes e as decisões das corporações relativas à estratégia de extensão de marcas.

O autor (I998, p. 227) ainda coloca que a extensão de marca é uma prática que vem crescendo e deve continuar, pois, para entrar em mercados em que estão ausentes, cada vez mais as empresas o fazem sob o nome de uma de suas marcas já existentes, em vez de criar uma nova marca para seu novo produto. Para o autor, a extensão de marca se tornou moeda corrente, deixando o apanágio do luxo para tornar-se uma prática generalizada.

Nescau, por exemplo, não é mais somente o conhecido achocolatado em pó, é também barra de chocolate, cereal matinal, bebida achocolatada pronta e sorvete. A prática da extensão tornou-se comum e invejada, negligenciando todos aqueles que acreditam no dogma do qual uma marca deve corresponder a um único produto.

Essa evolução natural é conseqüência direta da conscientização de que as marcas são o verdadeiro capital das empresas. Para capitalizar se faz necessário suporte, por isso o retraimento do portfolio das marcas e o não retraimento do número de produtos deixam claro que, quando uma mesma marca cobre um espectro mais amplo de produtos, a extensão de marca está sendo realizada.

Naturalmente, quando uma empresa possui uma marca consolidada e de forte repercussão em determinado mercado, a possibilidade de estender esta marca é cogitada. Algumas categorias mostram-se muito lógicas para destinar a extensão, mas qual delas oferecerá a melhor oportunidade? Esta resposta talvez 
esteja no profundo entendimento sobre quão similar são os pensamentos dos consumidores sobre estas categorias. De maneira geral, deve-se permear as categorias considerando a estrutura de cada mercado.

\subsection{EXTENSÃO DE MARCAS: IMPOSSÍVEL FICAR INDIFERENTE}

Em nosso cotidiano, respiramos marcas quase 24 horas por dia. Ao acordar, vamos ao encontro de nossa escova Oral B e a pasta de dentes Colgate, após o banho com shampoos e condicionadores Seda, sabonete Dove, utilizamos religiosamente nosso Rexona. Um café da manhã com sucrilhos Kellogg's e iogurte Danone nos deixará preparados para pegarmos nosso Ford e nos dirigirmos a mais um árduo dia de trabalho. Este simples exemplo nos faz imaginar quão numeroso é nosso contato diário com as mais diferentes marcas. Conhecidas, desconhecidas, íntimas, companheiras, enfim, é difícil mensurar, pois hoje é praticamente impossível encontrar um produto sem que este esteja entrelaçado a uma marca.

Troiano (2003, p. 3), em sua recente pesquisa realizada para entender o processo de extensão de marcas, afirma que estamos vendo acontecer uma total mudança de paradigma. Para ele, o século XXI não será de criação de novas marcas, mas sim de ampliação e maximização do uso de marcas já estabelecidas. Partindo desta afirmação, busca-se entender e fundamentar a razão pela qual a estratégia de extensão de marca vem sendo tão utilizada.

De acordo com Kapferer (I998, p. 230):

Estender a marca permite reforçar e nutrir o capital de imagem da marca. [...] De fato, é por meio dos produtos novos ou renovados assinados por ela que uma marca prova sua atualidade e sua pertinência, definindo-se como de seu tempo. Por isso a extensão de marcas, longe de enfraquecer a marca, freqüentemente a revigora e lhe dá nova juventude.

Quando se fala em fortalecimento da marca principal é fácil imaginar que os novos produtos, frutos da extensão, se transformarão em escudos de proteção para a marca principal. A exemplo da marca mundial Nike, sem dúvida, a cada novo produto lançado além do tradicional tênis, tais como roupas, relógios e acessórios para prática de esportes, há o fortalecimento da marca em questão. Outra forma de fortalecimento é a contribuição que cada produto lançado proporciona, a fim de reforçar os core values (valores centrais) da marca principal. 
Por exemplo, a cada novo produto da marca Brastemp que surge no mercado, a idéia de superioridade da marca é registrada pelos consumidores.

Kapferer (I998, p. 64) ainda cita que a proliferação de marcas novas se encerra a partir da necessidade de se capitalizar; a era da criação de dezenas de marcas para denominar novos produtos está encerrada.

Essa síndrome já atingiu a maioria das grandes corporações. A Nestlé, por exemplo, decidiu criar uma diretoria de marcas, a única com o poder de autorizar a criação de novas marcas em qualquer parte do mundo e as conseqüências desta estratégia são claras: a cada cem novos produtos lançados pela empresa, são criadas apenas cinco marcas.

Outro ponto importante a ser considerado e levantado por Kane (I987, p. 199-203) é o fato de as marcas, ao atingirem sua maturidade e caminharem para seu declínio, tenderem a perder grande parte de seu valor. Sendo assim, é necessário e complacente que o potencial da marca seja explorado durante sua vitalidade. Para ele, é justamente na exploração da vitalidade da marca que se inicia o processo de análise e de reflexão sobre a adoção da estratégia de extensão de marca.

Essa estratégia vem sendo muito explorada e utilizada. Os números são surpreendentes e, segundo pesquisa realizada pela Troiano Consultoria de Marcas (2003, p. I3), atualmente no Brasil $77 \%$ dos produtos comercializados nos supermercados e oferecidos ao consumidor são extensões de marcas já existentes. Este é um tema relativamente novo no mercado brasileiro e, apesar das extensões de marca terem início em meados de i960, foi em i980 que os estudos começaram a ganhar significância, sendo já bastante explorado em mercados como os Estados Unidos, onde o índice de extensão de marcas chega a 95\% segundo estudo realizado por Sheinin (I994, p. I-Io).

\section{3 EXTENSÃO DE MARCAS X EXTENSÃO DE LINHA}

A extensão de marca não deve ser confundida ou assimilada com extensão de linha, pois as diferenças além de teóricas são também práticas e impactam consistentemente nos resultados obtidos com esta estratégia. Existe uma perplexidade que ronda as corretas concepções sobre o lançamento de marcas e de produtos, bem como a extensão de marcas e a extensão de linhas de produtos, e tentaremos, por intermédio de alguns autores, esclarecer estas divergências.

Apesar de a maioria das obras reconhecidas em marketing consagrarem capítulos acerca da definição de novos produtos, deixam a desejar no que se refere ao lançamento de novas marcas, limitando-se por vezes à apresentação e escolha do nome para o novo produto, que não necessariamente trata de uma marca específica. Kapferer (I998, p. II9) afirma que esta incapacidade de distinguir o produto de sua marca deve-se ao fato de a maioria das grandes marcas, até en- 
tão, ser descoberta por acaso, ou seja, grande parte das marcas renomadas que estão no mercado atualmente foram concebidas pela mais ingênua sorte, sem estudo algum ou mesmo reflexão. A Coca-Cola, por exemplo, refletia nada mais do que o nome dos ingredientes de sua composição como produto; já Mercedes era o nome da filha do Sr. Daimler; Adidas, uma fusão do nome Adolphe Dassler; e assim inúmeros outros casos. Há décadas era preciso apenas dar um nome ao novo produto, pois sem ele não era possível a propaganda, que por sua vez apresentava os benefícios do produto e nada mais.

O mesmo autor (1998, p. I20) ainda afirma que, com o passar do tempo, este produto deve dar lugar a um produto superior, melhor, com mais desempenho, que herde a reputação e a notoriedade que foram adquiridas anteriormente; neste caso, os produtos podem mudar, mas as marcas devem permanecer.

Com isto constata-se que um novo produto lançado não significa necessariamente uma nova marca lançada, mas provavelmente uma nova marca lançada deve dar origem a um novo produto. Exemplificando, quando o sabão em pó Omo foi lançado, um novo produto surgiu no mercado, o sabão em pó veio em substituição ou complementação de uso ao sabão em barra, porém outros produtos destinados ao mesmo uso foram lançados pela Unilever, carregando a herança da marca Omo, segmentados por utilização (Omo cores, Omo máquina, Omo multiação etc.). Quando a marca Omo optou por disseminar outros produtos com a sua marca, ela realizou a extensão de linha e não a extensão de marca.

Para Kapferer (I998, p. 226), a extensão de linha designa o mesmo produto, porém com variações, no mesmo mercado. Essas variações podem ser quanto à embalagem, à cor, ao formato e ao sabor.

Troiano (2003, p. 2) difere extensão de marca e de linha de maneira muito clara; para ele, os produtos frutos da extensão de linha permanecem no mesmo território da marca principal, que pode ser classificado também como categoria. Um bom exemplo citado por ele são os sucos Maguary, uma marca de sucos concentrados que possui uma variedade de sabores, e cada um é uma extensão de linha da Maguary, pois permanecem no território de sucos. Observa-se que a marca Maguary, ao oferecer sucos ao consumidor, busca explorar a diversidade de sabores como diferencial de sua linha de produtos, estendendo assim sua linha e não sua marca. A adição de novos sabores às sopas Maggi ou Knnor também faz parte da estratégia de extensão de linha, já a passagem dessas marcas para a categoria de pratos prontos (risotos, fatiados e congelados) caracterizaria a extensão de marca que, segundo Aaker (1998, p. 219), é a utilização de marcas já existentes em um mercado/categoria em que esta ainda não atua. A extensão de marca é caracterizada por "aventurar-se" em uma categoria ou território diferente da categoria da marca principal. Por exemplo, a marca Dove ao lançar shampoo, condicionador e creme hidratante está praticando a extensão de mar- 
cas, pois começa a atuar em categorias diferentes da categoria de sabonetes; já ao permanecer na categoria de sabonetes, lançando Dove sabonete para pele seca, ou Dove sabonete esfoliante, ela está praticando a extensão de sua linha de sabonetes e não da marca Dove.

Kapferer (I998, p. 228) alerta que ainda existem dúvidas sobre a delimitação de cada estratégia, ou seja, até que ponto uma estratégia complementa, antecede ou mesmo se entrelaça na outra, uma vez que as fronteiras que as dividem ainda são imprecisas, porém de forma alguma isso invalida a existência dos dois conceitos bem diferenciados e cujos protótipos não podem ser assimilados.

De acordo com Tauber (I98I, p. 37), a extensão de marca deve ser trabalhada de forma específica e somente quando necessário, pois a partir dela a empresa se propõe a entrar em um novo negócio, por meio da alavancagem de seu ativo mais valioso. O mesmo autor identifica, ainda, quatro tipos de estratégias visando o lançamento de novos produtos, entre elas, destacar-se-á a extensão de marca e a extensão de linha:

- Novo produto tradicional: Diz respeito à criação de uma nova marca pela empresa para entrada deste produto em um mercado ainda não explorado.

- Produto de flanco: Diz respeito à criação de uma nova marca pela empresa para entrada deste produto em um mercado já explorado.

- Extensão de linha: Diz respeito à utilização de uma marca já trabalhada pela empresa em uma categoria de produtos que esta já atua.

- Extensão de marca: Diz respeito à utilização de uma marca já trabalhada pela empresa em uma nova categoria de produtos em que esta não atua.

Os conceitos apresentados pelo autor podem ser traduzidos de forma simples no quadro abaixo.

\begin{tabular}{lll}
\hline $\begin{array}{l}\text { TIPOS DE LANÇAMENTOS } \\
\text { DE NOVOS PRODUTOS }\end{array}$ & \multicolumn{1}{c}{ MARCA } & MERCADO/CATEGORIA \\
\hline $\begin{array}{l}\text { 1. novo produto tradicional } \\
\text { 2. produto de flanco }\end{array}$ & criação de nova marca & não explorado \\
3. extensão de linha & criação de nova marca & já explorado \\
4. extensão de marca & marca existente & já explorado \\
\hline
\end{tabular}

Com a verificação desses modelos é possível, a partir de agora, distinguir as diferenças entre as duas estratégias. Considerando os aspectos da extensão de linha, percebe-se que esta visa atender a novos usuários; por exemplo, a linha de sucos Maguary acrescenta em seu portfolio os sabores morango e uva, visando 
atingir aqueles consumidores que não gostavam dos sabores até então oferecidos. A extensão de marca pretende atender novos usuários da marca por exemplo, o consumidor que é usuário dos lápis da marca Faber-Castell; logo utilizará também as borrachas e canetas do mesmo fabricante, pois já conhece a marca.

Após esclarecer estes pontos relevantes, que visam dar continuidade ao entendimento acerca da estratégia de extensão de marca, prossegue-se com uma reflexão sobre a lógica que abarca a estratégia de extensão.

\subsection{A LÓGICA DA EXTENSÃO DE MARCAS}

A estratégia de extensão de marca, para que seja bem realizada, deve seguir uma lógica que faça sentido para o consumidor. Kapferer (I998, p. 258) afirma que a precondição para qualquer extensão é conhecer bem a sua marca. Pode parecer óbvio, mas a necessidade de se entender a fundo o que a marca oferece para seus consumidores, qual é sua personalidade, suas potencialidades latentes é extremamente importante para que a estratégia seja bem-sucedida. $\mathrm{O}$ autor coloca ainda que a segunda etapa do processo de investigação acontece com a extração e identificação dos traços distintivos da marca e a exploração destes.

Troiano (2003, p. I2) realizou uma pesquisa de campo em que 64 categorias diferentes foram auditadas e destas categorias extraiu-se 456 marcas, que por sua vez deram origem a 2.228 produtos. Nesta pesquisa, que vislumbra a aplicação da estratégia de extensão de marcas na prática, pode-se identificar a lógica utilizada hoje pelo mercado na atividade da extensão. Foi identificado nesta pesquisa o tipo de conexão entre a marca principal e suas extensões, divididos em oito princípios:

I. Mudança de apresentação: A extensão de marca é uma reapresentação do produto principal, em um novo conceito de embalagem e/ou de forma. $\mathrm{O}$ adoçante Doce Menor, por exemplo, se apresentava apenas na versão gotas, passando a estender sua marca também para a versão pó, mudando assim a apresentação do produto.

2. Preservação do ingrediente: Neste caso, a extensão carrega o ingrediente principal do produto primogênito. Leite Moça, por exemplo, usou seu ingrediente principal para lançar as extensões Moça Fiesta, que são produtos prontos para festas como brigadeiros, cajuzinhos etc.

3. Complementação de uso: São as extensões que trabalham em categorias de produtos complementares à da marca principal. Colgate, ao lançar a escova de dente e o fio dental, proveu uma complementação no uso de seu produto principal, o creme dental. 
4. Conservação da forma: Neste caso, as extensões apenas se encarregam de manter a forma física ou tipo de embalagem. É o que acontece com os produtos enlatados, da marca Etti, por exemplo, que estendeu sua linha em inúmeros produtos como molhos, ervilhas, milho verde etc., todos enlatados.

5. Concentração no público-alvo: Neste caso, o foco das extensões é o consumidor, todos os produtos frutos da extensão são concentrados no target da marca principal. Um exemplo são as extensões da marca de iogurte Chambinho, que partiu para a categoria de sorvetes buscando o público infantil.

6. Aplicação de expertise: Neste caso, o know-how percebido pela marca é transferido para outros produtos que exijam as mesmas competências tecnológicas ou de serviços. É o que acontece no mercado de eletrodomésticos e linha branca; a marca Brastemp, além de assinar as lavadoras, assina também fogões, microondas, secadoras etc.

7. Transferência de personalidade: Neste caso, os core values (valores centrais) da marca principal precisam estar presentes nos produtos frutos da extensão. Um exemplo é a marca Nike, que utiliza sua personalidade de marca para dar vida a outros produtos; vista como uma marca de esportes, de maneira simplista, a marca Nike pode dar origem a bonés, camisetas para corrida, relógios esportivos etc.

8. Uso do poder: Neste modelo, identificado na pesquisa, se encaixam todas as outras extensões, que usam o poder ou a força que sua marca apresenta, para gerar extensões que muitas vezes não estão totalmente adequadas e alinhadas ao produto principal.

Partindo da apresentação desses conceitos, pode-se perceber que a extensão de marca gira em torno de três grandes elementos: marca - produto - consumidor, derivando assim as extensões:

\section{CONSUMIDOR}

- Concentração no target (público-alvo)
- Mudança de apresentação

- Preservação do ingrediente

- Complementação de uso

- Conservação da forma 
Para melhor avaliação da estratégia de extensão de marcas e de seu entendimento, são apresentados a seguir os riscos e os benefícios decorrentes de sua utilização.

\subsection{OS RISCOS DA EXTENSÃO DE MARCAS}

Até este ponto, a abordagem girou em torno do conhecimento sobre a estratégia de extensão de marca, mas para se ter uma visão ampla desta estratégia é preciso, não obstante, tomar conhecimento também de seus riscos.

Um dos autores mais conhecidos, e que determinantemente condena a estratégia de extensão de marca é Al Ries (2000, p. 107). O autor afirma ser esta uma estratégia bastante arriscada e que pode comprometer o patrimônio da marca: "Há uma pressão irresistível para estender o patrimônio líquido da marca". Ele afirma que a empresa concentra sua marca em um produto bastante rentável e, posteriormente confiando no sucesso alcançado, a mesma empresa quer abarcar muitos produtos com a mesma marca e termina perdendo dinheiro. Ele cita ainda alguns exemplos clássicos de extensão de marca feita por empresas que procuraram ampliar sua linha de produtos e amargaram fracassos: o perfume Channel para homens; as meias-calça Bic; a colônia Adidas; o vinho Pierre Cardin; os sapatos Levi's. Para o autor quando se procura ser tudo para todos, é inevitável acabar em dificuldades.

Certamente há de se ter precauções e há de se considerar inúmeros pontos antes do desenvolvimento da estratégia de extensão de marca. A marca não pode ser estendida sem reflexões profundas de sua personalidade e sua visão por parte dos consumidores. Kapferer (I998, p. 26I) também faz alertas com relação à extensão de marca; para ele, a extensão é um ato estratégico que compromete o futuro e o capital da marca. Trata-se de um ato delicado, daí as precauções que constituem uma sadia metodologia de estudos sobre o potencial da extensão. O autor apresenta os erros desta estratégia, cujos apelos são tão fortes quanto perigosos:

I. Visão limitante da marca: Muitas empresas possuem uma visão reduzida de suas marcas, tomando-as como nomes descritivos ou puramente gráficos. Alguns nomes de marcas surgem em função dos primeiros produtos lançados, como no caso do sabonete Palmolive, quando lançado o sabonete possuía agentes emolientes vindos dos extratos de oliva, com o passar do tempo a marca foi se estendendo para categorias como a de shampoos e condicionadores, não limitando a marca aos componentes da oliva e passando para uma visão baseada no que a marca realmente significava. Ou seja, um dos riscos inerentes à extensão de marcas é justamente limitar-se ao nome des- 
critivo da marca, o que poderia ter sido um fracasso caso a Palmolive lançasse shampoos e condicionadores com extrato de oliva.

2. Enclausuramento da marca: Quando uma marca possui uma imagem desgastada e envelhecida, as empresas se sentem tentadas a abandonar aquela marca e criar uma nova para seus produtos modernos, com o temor de que se $o$ antigo nome fosse usado, os novos produtos poderiam também parecer envelhecidos. Essa ação enclausura a marca em um gueto, dissociandoa dos novos produtos e contribuindo para que ela se torne cada vez mais antiga, chegando ao seu desaparecimento.

3. Extensão destrutiva: Quantas empresas estenderam suas marcas para o segmento de produtos light e de baixa caloria, quando perceberam o grande crescimento e expansão do setor. Para algumas delas, entretanto, isso foi um erro. As marcas que estão ligadas ao sabor único e diferenciado podem correr um risco muito grande entrando na categoria light, isso porque essa categoria já é vista pelo consumidor como produtos menos saborosos. O mesmo ocorre com extensões que fogem totalmente do significado e da identidade da marca principal. Isso ocorreu quando o chá Lipton estendeu sua marca para o mercado de sopas, a impressão dos consumidores era de que o chá teria se tornado um pouco salgado, transferência maléfica vinda da extensão. Nestes casos, a extensão pode prejudicar e até mesmo destruir a marca principal.

4. Desconhecimento da identidade da marca: A Bic fez sua fortuna comercializando canetas esferográficas, isqueiros e lâminas, porém não teve o menor êxito ao oferecer para o consumidor perfumes baratos e pranchas de windsurfe. Este fracasso se deve, em parte, a um erro de diagnóstico sobre o que é a marca Bic. A marca é o princípio gerador de produtos e, ao contrário das aparências, não é a descartabilidade, o descartável é a conseqüência do princípio e não o princípio.

Os riscos são verdadeiros, eles efetivamente existem, mas a ponte entre $o$ recuo e o sucesso desta estratégia é bastante longa e possibilita muitas oportunidades de crescimento por meio da extensão de marca bem feita e corretamente direcionada.

\subsection{OS BENEFÍCIOS DA EXTENSÃO DE MARCAS}

São inúmeros os benefícios da correta utilização da estratégia de extensão de marca. Além do fortalecimento da marca principal citado por Kapferer (I998, p. 228-23I), existem outros benefícios enumerados por ele discriminados a seguir. 
I. Manter a marca viva: As empresas compreendem que manter uma marca viva não se resume ao ato de comunicação, pois as marcas constituem um comportamento; a marca somente se mostra viva se dá provas de sua missão e questiona constantemente o produto que carrega. É justamente por meio de sua inovação que a marca permanece atual, não envelhecendo ao longo do tempo; ela precisa, portanto, acompanhar os consumidores, suas mudanças, seus novos hábitos, suas expectativas. Todas as marcas que se fixam em um único produto, confiando somente em sua comunicação para se manter atual, acabam por tornar-se presas fáceis das marcas concorrentes.

2. Minimizar os custos da publicidade: A lógica da marca é sempre competitiva, buscando sempre ganhos altos em produtividade e economias de escala, isto somente é possível estendendo sua ambição de participação não apenas no mercado local, mas no nacional e porque não no mercado global. A publicidade é o meio mais eficaz de atingir essa camada cada vez maior de potenciais compradores e, para se chegar à altura dos concorrentes, os gastos em publicidade ficam cada vez maiores. Os altos custos publicitários tornam impossível a sustentação de muitas marcas, tornando necessária a concentração dos recursos somente em algumas grandes marcas. E são justamente estas marcas que proverão sua atualidade e pertinência com a introdução de produtos diversificados e inovadores no mercado.

3. Defender a permanência de uma marca ameaçada: A extensão de marcas é uma das únicas maneiras para se defender a permanência de uma marca ameaçada em um mercado base. Os mercados commodities são de difícil diferenciação e compostos por grande número de concorrentes. Normalmente os produtos estabelecem estratégias de preços baixos, devido a sua pouca diferenciação; apenas uma estratégia bem aplicada de extensão poderá salvar um produto, dando a ele nova vida e reconhecimento por intermédio da marca.

4. Maximizar o capital de imagem acumulado: Os atributos de muitas marcas são pertinentes em outras categorias de produtos que não a de origem. Este aspecto se aplica principalmente ao mercado business to business, quando as marcas fazem associações com outros produtos por tempo limitado, "emprestando" sua imagem para gerar lucratividade e renda ao produto de outra empresa. Por exemplo, o lançamento do Renault Clio Boticário, a marca Boticário foi utilizada como forma de participação na associação e direcionamento do automóvel para o público feminino.

5. Perceber que a extensão permite deslanchar a marca de um só produto: Todos os produtos estão submetidos ao ciclo de vida e, então, à obsolescência; portan- 
to, quando um nome de marca está ligado por muito tempo a um único produto, submete-se esta marca ao risco da própria obsolescência. Neste caso, a extensão de marca é uma maneira de fazê-la durar, por isso a importância estratégica da diversificação de marca para desencadeá-la e dar-lhe sentido maior.

Concordando com esses benefícios, Troiano (2003, p. 3) também apóia a estratégia de extensão de marca como forma de fortalecer a marca principal, além de incrementar os negócios existentes e gerar novos negócios. Para o consultor, as extensões servem também para entrar em categorias de maior valor agregado, capitalizando assim a marca em questão. Por exemplo, o caso de extensão da marca Dona Benta, que produzia primeiramente apenas farinha de trigo, uma categoria de produtos considerada commodity, por possuir baixo valor agregado e muitos concorrentes. A extensão de marca a levou a lançar produtos como massas prontas para bolo, massas para bolinhos de chuva e fermento em pó, categorias que permitem margens de lucros mais atraentes, todos estes produtos carregando a marca Dona Benta, já consolidada e conhecida como farinha de trigo de alta qualidade.

Swaminathan (2003, p. 435) afirma que a extensão de marca é uma estratégia extremamente vantajosa por reduzir os custos de introdução de uma nova marca no mercado, além de aumentar muito a probabilidade de sucesso de um novo produto em outra categoria, uma vez que este carrega um nome de marca já conhecido. Outra perspectiva destacada pela pesquisadora é o fato da extensão de marca, se presente em muitas categorias, ajudar na construção do brand equity e na valorização daquela marca no mercado. Ainda de acordo com Swaminathan (2003, p. 432-433) os produtos frutos da extensão carregam todas as associações e estão ligados às cognições que o consumidor faz a partir da marca principal, carregando de maneira muito forte as lembranças e percepções do consumidor com relação àquela marca, ligações estas que demorariam anos e custariam fortunas para serem construídas. A introdução de um novo produto com um nome de marca já conhecido irá resultar no reconhecimento de sensações, crenças e experiências associadas primeiramente à marca principal e posteriormente às suas extensões.

Para Troiano (2003, p. 35) as extensões de marca vieram para ficar; pois, além de serem consideradas por ele muralhas de proteção, permitindo que a marca ganhe força e se torne cada vez mais conhecida por meio da sua utilização em diversas categorias relativas, elas também não apenas rentabilizam os investimentos em marketing, como diminuem a tensão de escolha do consumidor no ponto de venda. 


\section{7 O CONSUMIDOR E A EXTENSÃO DE MARCAS}

O consumidor exerce um papel fundamental no exercício da estratégia de extensão de marca, pois é a partir de sua percepção que a estratégia pode ser bem ou malsucedida. Aaker e Keller (I990, p. 27-5I) discorrem sobre qual é a percepção do consumidor a respeito de extensões de marcas. Os resultados apresentados pelos pesquisadores são os seguintes:

- A transferência de atributos entre a marca principal e a extensão de marca pode ter efeitos tanto positivos quanto negativos. A transferência de um atributo que parece incongruente com o produto resultante da extensão pode gerar uma visão negativa desta extensão por parte dos consumidores.

- A transferência da percepção de qualidade da marca principal para a marca estendida é influenciada positivamente quando as categorias dos produtos apresentam como características o fato de serem complementares e/ou substitutas.

- Na visão dos consumidores, quanto mais difícil de produzir as extensões, melhores são as atitudes com relação à marca. Esse fenômeno ocorre em razão da percepção do consumidor de que um produto que é facilmente fabricado, e está sendo introduzido pela extensão de uma marca de qualidade, representa uma iniciativa da empresa de cobrar preços abusivos, capitalizando por meio da marca.

- Verificando os efeitos da percepção do consumidor a respeito da marca principal, os autores concluem que quanto maior a percepção de qualidade, maior a chance de o consumidor transferir as qualidades da marca principal para a extensão.

- A percepção do consumidor a respeito da similaridade entre a marca principal e a extensão, ou seja, a transferência da capacidade de manufatura do produto principal para a extensão, influencia positivamente as atitudes com relação à extensão de marca.

Usando as palavras "brands have boundaries", Aaker e Keller (I990 p. 27-5I) apresentam esta idéia: apesar de as marcas de alta qualidade poderem ser estendidas, além do que poderia uma marca de qualidade média, existem limites para o uso dessa estratégia. Dessa forma, a empresa precisa estar atenta para os limites que existem na adoção dessa estratégia. Além desses limites, as empresas correm o risco de criar extensões de marca que não obtenham sucesso e que acarretem impactos negativos na marca principal.

Swaminathan (2003, p. 435) apresenta pesquisa em que são analisados os efeitos de reciprocidade entre a marca principal e as extensões. Esses efeitos são 
responsáveis pela percepção do consumidor a respeito do sucesso da extensão e como isso impacta na percepção da marca principal.

De acordo com Schifman e Kanuk (2000, p. I26), a qualidade percebida de um produto é resultado de uma série de julgamento a respeito de uma variedade de sinais e informações que os consumidores associam aos produtos; esses sinais podem ser intrínsecos (características físicas do produto como tamanho, cor, sabor ou aroma) ou extrínsecos (sinais externos do produto como preço, imagem da marca, imagem da empresa e até da loja). "Na ausência de experiência real com o produto, os consumidores freqüentemente avaliam a qualidade com base em sinais extrínsecos." Segundo os autores, o processo de transferência de percepções da marca principal para a extensão de marca se dá por meio das dimensões extrínsecas da marca principal, mais precisamente à imagem da marca.

Seguindo essa mesma linha, Swaminathan (2003, p. 440) afirma que, de acordo com essas percepções, o consumidor irá construir uma imagem da extensão de marca, que permanecerá até o momento em que ele, o consumidor, efetivamente experimente o produto fruto da extensão.

\section{CONSIDERAÇÕES FINAIS}

Não seria possível concluir este estudo sobre extensão de marca sem sinalizar os perigos iminentes e atuais, originários da "moda" em se praticar essa estratégia. A verdade é que muitas vezes se escolhe a extensão de marca por preguiça ou conformismo, sendo que, na maioria destes casos, seria mais plausível e adequado o lançamento de uma nova marca, que sem dúvida demandaria maiores esforços, trabalho, energia e, claro, mais investimento.

Entretanto é na obtenção de um portfolio com marcas fortes e consolidadas que descansa o futuro das empresas. Existe uma oportunidade não-medida, não-calculada dos benefícios resultantes da extensão de marca quando uma empresa opta por não fazê-la, deixando para trás a possibilidade de obter maior cobertura do mercado, crescimento empresarial e fortalecimento de suas principais marcas.

Toda extensão está semeada de armadilhas, mas está também repleta de ganhos; essa fronteira que divide a má da boa extensão é estabelecida a partir do profundo conhecimento da marca em questão, incluindo sua personalidade, sua imagem, suas percepções etc.

Ao estudar a complexidade que envolve a construção de uma marca, é inevitável ser resistente e prudente na prática da extensão, e justamente essa prudência acarretará as reflexões necessárias, inerentes a essa decisão. 
O estudo apresentado tentou minimizar as dúvidas e incertezas acerca da estratégia de extensão de marca e, não obstante, buscou encorajar essa prática, contudo alertando sobre os devidos cuidados a serem tomados.

Pode-se concluir que a exploração sobre os limites que envolvem a estratégia de extensão de marca é vasta, ampla e muito extensa, e certamente vai além do apresentado neste estudo; todavia a confluência destas informações possibilitou um novo olhar, de um novo prisma, acerca desta estratégia.

Optar pela extensão de marca pode ter a natureza de transformar uma marca forte em uma marca "guarda-chuva", os exemplos da aplicação dessa estratégia de maneira bem-sucedida são inúmeros, quase que infinitos. Os benefícios são incontestáveis para a empresa que capitaliza seus recursos, evidentes para a marca, que se vê fortalecida, e também para o consumidor, que tem suas tensões de escolha reduzidas a partir de relação já existente com a marca ao adquirir o novo produto.

Conclui-se, portanto, que dentre todos os benefícios apresentados na prática da extensão - tais como redução dos gastos com publicidade; agilidade no lançamento de produtos; capitalização de recursos etc. -, pode-se destacar o grande, senão o maior benefício que a extensão projeta: o fortalecimento da marca.

Quando se fortalece uma marca, mantendo-a viva, existe a preservação da "espécie" da marca. O nascimento e proliferação de novas marcas, que carregam consigo o nome (ou sobrenome) da marca-mãe planeiam um círculo de crescimento e prosperidade que conservará a marca viva, por gerações.

\section{REFERÊNCIAS}

AAKER, David. Criando e administrando marcas de sucesso. São Paulo: Futura, 200I.

- Marcas brand equity: gerenciando o valor da marca. São Paulo: Negócio, I998.

; KELLER, Kevin L. Consumer evaluation of brand extentions. Journal of Marketing, v. 54, p. 27-5I, I990.

KANE, Chester L. How to increase the odds for successful brand extension. International Journal of Product Innovation Management, v. 4, Issue 3, p. I99-203, I987.

KAPFERER, Jean-Noël. As marcas. Capital da empresa: criar e desenvolver marcas fortes. Porto Alegre: Bookman, 1998.

KOTLER, Philip. Administração de marketing. São Paulo: Atlas, 2000.

- Marketing para o século XXI. São Paulo: Futura, 2003.

PALLADINO, Andrew. Businessweek reports interbrands annual ranking of "the best global brands". New York: Businessweek Magazine, Special Edition, August 2nd issue, 2004. PEREZ, Clotilde. Signos da marca: expressividade e sensoriedade. São Paulo: Pioneira, Thomsom Learning, 2004.

RIES, Al. As 22 consagradas leis de marcas. São Paulo: Makron Books, 2000. 
— ; TROUT, Jack. Posicionamento: a batalha pela sua mente. São Paulo: Pioneira, I997.

SCHIFMAN, Leon G.; KANUK, Leslie Lazar. Comportamento do consumidor. Rio de Janeiro: LTC, 2000.

SHEININ, A. Daniel. Extending brands with new product concepts: the role of category attribute congruity, brand affect, and brand breadth. Columbia University. Journal of Business Research, 3I, p. I-I0, I994.

- The effects of experience with brand extensions on parent brand knowledge. Journal of Business Research, v. 49, issue I, p. 47-55, 2000.

SWAMINATHAN, Vanitha. Sequential brand extensions and brand choice behavior. Journal of Business Research, v. 56, issue 6, p. 43I-442, 2003.

TAUBER, Edward M. Brand franchise extention: new product benefits from existing brand names. Business Horizons, Greenwich, v. 24, n. 2, p. 36-4I, I98I.

TROIANO, Jaime. A grande familia: ampliando os domínios da marca. São Paulo, 2003. (Pesquisa realizada pela Troiano Consultoria de Marcas).

- Revista Mercado Global. Edição Especial: Marcas. Edição n. II4, Io trimestre de 2004 .

TRAMITAÇÃ O

Recebido em 14/12/2001

Aprovado em 10/07/2006 
Copyright of Revista de Administração Mackenzie is the property of Universidade Presbiteriana Mackenzie, RAM-Revista de Administracao Mackenzie and its content may not be copied or emailed to multiple sites or posted to a listserv without the copyright holder's express written permission. However, users may print, download, or email articles for individual use. 